ficamente cognoscible para llegar a una verdad más profunda: Dios, la experiencia interior, la vivencia individual en la que encontramos el sentido de la vida y que, por otro lado, es ya la misión de la filosofía, pues ella es para Jaspers "aquel pensar que, en posesión del saber universal científico, se cerciora de lo que por esencia escapa a ese saber. Pero sin el conocimiento objetivo de la ciencia, en cuanto base que la filosofía no viola, ésta no llega a la verdad que le es propia" (p. 203). ¿No es esta filosofía, a pesar de su base kantiana -científica-, irracionalista? ¿No es filosofar como si Hegel no hubiese exis. tido, es decir, como si el sentido histó. rico y la positividad de la realidad no existieran y tuviéramos que buscar algo "más allá"? ¿Y Nietzsche? ¿Volvemos a filosofar como Wolff? Quizá lo único que estamos expresando, al fin y al cabo, es esa misma objeción en la que Husserl y Jaspers, Rickert y Jaspers se encontraron y que hoy en día se nos presenta sin solución: la cientificidad de la filosofía.

Pensamos que este libro, en general, muestra de una manera sencilla y clara -no por ello simple- la filosofía de Jaspers y que, de un modo u otro, cumple con la intención que se había propuesto: situar la filosofía de Jaspers y hacer patente la base kantiana de su pensamiento. Por otro lado, al problematizar, sugiere, invita a la lectura de este pensador, lo cual redobla los merecimientos del libro.

\section{Alberto Constante}

J. G. Fichte, Gesamtausgabe der Bayerischen Akademie der Wissenschaften. Werkeband 5: Wer- ke 1978-1979. Herausgegeben von Reinhard Lauth und Hans Gliwitzky. (J. G. Fichte, Obras Completas editadas por la Academia de las Ciencias de Baviera. Tomo 5: Obras de 1978-1979. Editadas por Reinhard Lauth y Hans Gliwitzky.) Friedrich Frommann Verlag (Günther Holz. boog), Stuttgart-Bad Cannstatt, 1977, $480 \mathrm{pp}$.

El presente volumen de la ya famosa edición crítica y monumental de las Obras Completas de Fichte, preparada por el maestro Reinhard Lauth, sin duda actualmente el especialista mundial número uno en el conocimiento de todo lo relativo a Fichte: vida, ideas y vicisitudes, contiene propiamente una sola obra, Das System der Sittenlehre (El sistema de la doctrina $\longrightarrow$ teoría- moral), que en otras referencias aparece también con el nombre de Ética y de Filosofía prác. tica. Creo necesario o conveniente señalar esto, porque los otros escritos incluidos aquí son más bien 2 opúsculos y 2 publicaciones brevísimas (3 páginas cada una), que en total suman apenas unas 57 páginas -quitados los prefacios o presentaciones de los editores, mien. tras que aquélla cubre nada menos que 317. La razón de haberlos publicado juntos es, sin duda, la época en que aparecieron, aunque podría pensarse en alguna relación temática, ya que los escritos se refieren al tema del ateísmo, es decir, al famoso problema del Atheismusstreit (Disputa sobre ateísmo), en que se vio envuelto Fichte.

El sistema de la doctrina -o teoríamoral es como la aplicación o realización del principio fundamental de la filosofía de Fichte en el campo práctico 
o de las costumbres, desarrollado y llevado a cabo con la reciedumbre y solidez lógica de las diversas versiones de La doctrina de la ciencia (1801, 1804, 1811, etcétera) o de El fundamento de toda la doctrina de la ciencia (1797). Algo de esto se deja ver en el título completo de la obra: El sistema de la teoría moral según los principios de la doctrina de la ciencia.

En el prólogo a la obra los editores, con cierta extrañeza de mi parte, casi no se ocupan de la obra misma, es decir, de señalar, por ejemplo, su estructura, su constitución formal, su método, sus temas en general y en particular, su sitio en la obra del filósofo, su importancia o su influencia, etcétera. Las únicas breves indicaciones al respecto son éstas: "Según la concepción originaria de Fichte, del año 1974, una doctrina moral, como teoría especial, pertenecía ya a la doctrina entera de la ciencia. Según la división hipotética de la doctrina de la ciencia, hecha en el $\S 8$ del escrito 'Sobre el concepto de la doctrina de la ciencia', debía ella ser desarrollada en la segunda parte, práctica, de la doctrina de la ciencia, a la que tenía que servir de fundamento el 'concepto de la tendencia, que debía demostrarse como necesaria'. En esa parte se establecerán una nueva y totalmente determinada teoría de lo agradable, de lo bello y de lo sublime, de la regularidad de la naturaleza en su libertad, de la teología, del llamado sentido común o del sentido natural de la verdad y finalmente un derecho natural y una doctrina moral, cu. yos principios son no sólo formales, sino materiales" (p. 4-5).

¿Por qué los editores hacen sólo estas consideraciones generales? Tal vez porque suponen con razón que ésta no es su tarea, pues no dan a conocer la obra por primera vez, presentando al públi- co su valor e importancia. Sin embargo, en cierta forma sí lo hacen; por lo menos con relación a algunos aspectos, al presentar las más importantes reseñas que motivó la aparición de la obra, entre ellas la de Schleiermacher, tal vez la más valiosa; también se ocupan del problema de una supuesta segunda edición, quizá fraudulenta.

$\mathrm{Si}$ los editores creyeron propio no ocuparse de presentar la obra misma, pienso que menos le compete a un reseñante hacerlo. Sin embargo, dado el conocimiento relativamente escaso de la filosofia de Fichte en general y de esta obra en particular en el ámbito de habla hispana - mucho más en español, pues, que yo sepa, no ha sido traducida a este idioma-, voy a ofrecer por lo menos los nombres de los temas, sacándolos del índice.

La obra se divide en tres capítulos. El primero se ocupa de la "deducción del principio de la moralidad". El segundo trata sobre "Deducción de la realidad y aplicabilidad del principio de la moralidad". Comprende, entre otros, los siguientes puntos: "Deducción de un objeto de nuestra actividad en general"; "Deducción de la causalidad real del ser racional"; "Determinación de la causalidad del ser racional por su carácter interno"; la "Libertad y la facultad superior de deseo"; "División de la teoría moral". El tercer capítulo tiene por tema: "Aplicación sistemática del principio de la moralidad o la teoría mo. ral en sentido estricto". El primer inciso versa sobre estos puntos: las condiciones formales de la moralidad de nuestras ac. ciones y su sistematización; la voluntad en especial; la causa del mal en el ser racional finito. El segundo inciso es un recuento de la materia de la ley moral, - sea, una perspectiva sistemática de nuestros deberes y hace la formulación 
sistemática de las condiciones de la yoidad, en su relación con el impulso hacia absoluta autonomía. En el tercer inciso se exponen: la teoría de los deberes pro. piamente dicha, la división de éstos, asi como los deberes generales condicionados y los especiales; un panorama de los deberes generales inmediatos y su división; los deberes con respecto a la libertad formal de todos los seres racionales; el deber de entender inmediatamente la moralidad e impulsarla; un panorama de los deberes especiales; la relación de los deberes especiales con los generales y la división de aquéllos; los deberes del hombre según su especial estado natural; los deberes del hombre según su oficio particular. División de los posibles oficios humanos: del sabio, del maestro-deescuela moral, del artista, del empleado público, de las clases populares inferiores.

El grupo de escritos que tienen relación con el problema del ateísmo - es decir, la censura o incriminación contra Fichte y contra un colega suyo de negar o poner en duda algo relativo al concepto mismo de Dios o a su conocimiento o fe en El- comprende los siguientes: "Sobre el fundamento de nuestra creencia en un gobierno divino del mundo", "Anuncio [de la apelación al público]", "Rectificación de una rectificación" y "Apelación al público sobre las expresiones ateístas atribuidas a él."

La presentación de los artículos hecha por los editores se ocupa en general de problemas históricos relativos tanto a las aclaraciones de quienes editaban el "Diario filosófico" (Fichte y Niethamer)' donde se publicó el primero, como a las declaraciones oficiales de las autoridades civiles que en general condenaron las ideas expresadas en él y mandaron prohibir y confiscar los números del diario. Aquí se destaca, por cierto, que tanto el rey de Prusia Federico Guillermo III, como las demás autoridades civiles y espirituales del reino, se negaron a secundar la actitud de las de Sajonia, a las que contrainvitan a no prohibir ni confiscar aquellos escritos. Respecto a las ideas mismas en general, y en particular a las presuntas expresiones de ateís. mo, los editores reproducen, sobre todo, las enérgicas y a veces violentas respuestas de Fichte a las incriminaciones de ateísmo y' otras valiosas defensas de al. gunos contemporáneos. Si echamos un vistazo a los escritos, comprobamos que se trata de análisis y juicios filosóficos, lo más rigurosos posibles -quien cono. ce ya el razonar de Fichte lo confirmará-, acerca del verdadero y posible con. cepto de Dios, de su demostración real y eficaz, del alcance y naturaleza de la fe en Él, etcétera. $Y$ en cuanto al ateís. mo, casi todos, pero en especial los fi. lósofos y los que estudiaron el caso con las armas de la recta razón, no sólo lo declaran libre de tal incriminación, sino que, fundados en sus explicaciones y declaraciones, lo consideran religioso y pia. doso en el verdadero sentido.

Creo, para terminar, que con este volumen los interesados en conocer en forma directa las ideas de Fichte verán satisfecho plenamente su interés por lo que respecta al pensamiento moral y religioso.

BerRabé NaVarRo 